International Journal of Automotive and Mechanical Engineering (IJAME)

ISSN: 2229-8649 (Print); ISSN: 2180-1606 (Online); Volume 8, pp. 1151-1161, July-December 2013

(OUniversiti Malaysia Pahang

DOI: http://dx.doi.org/10.15282/ijame.8.2013.6.0094

\title{
EFFECTS OF COPPER AND MAGNESIUM ON PHASE FORMATION MODELING AND MECHANICAL BEHAVIOR IN AL-CU-MG ALLOYS
}

\author{
N. Nafsin and H. M. M. A. Rashed \\ Department of Materials and Metallurgical Engineering, \\ Bangladesh University of Engineering and Technology, \\ Dhaka - 1000, Bangladesh \\ Email: hrashed@mme.buet.ac.bd \\ Tel/Fax: +88029665618
}

\begin{abstract}
The current work emphasizes the establishment of a relationship between microstructure, and copper and magnesium addition in aluminum based alloys. Aluminum alloys containing 4 and $6 \%$ copper and 0.50 and $1 \%$ magnesium were cast from commercially pure aluminum ingots and homogenized at $400^{\circ} \mathrm{C}$. Images of the microstructures of the as-cast and homogenized alloys were acquired, and image analysis of the phases was performed on the acquired images to obtain area fractions of the phases present in the microstructure. Using the CALPHAD modeling method, thermodynamic modeling of the alloys was carried out in the equilibrium cooling condition since after homogenization for a prolonged time the alloys should reach a close to equilibrium cooling condition. Phase fractions predicted in modeling were matched closely with image analysis data, given that phases present in the homogenized alloys can be interpreted through modeling in the equilibrium cooling condition. EDX analysis of the samples identified the phases present in the alloys as $\mathrm{Al}_{2} \mathrm{Cu}, \mathrm{Mg}_{2} \mathrm{Si}$ and $\mathrm{Al}_{7} \mathrm{Cu}_{2} \mathrm{Mg}$. With increasing copper content, it was found both in modeling and experimentally that the amount of $\mathrm{Al}_{2} \mathrm{Cu}$ phase increased, which improved the hardness values of the alloys. However, in the homogenized condition, the hardness values slightly decreased compared to those of the as-cast condition due to retention of a lower fraction of $\mathrm{Al}_{2} \mathrm{Cu}$ phase in the homogenized condition. This was ascertained in the modeling of the alloys. In contrast, $\mathrm{Mg}_{2} \mathrm{Si}$ and $\mathrm{Al}_{7} \mathrm{Cu}_{2} \mathrm{Mg}$ phases were formed when magnesium was added in the predefined amount; however, these phases were not found to be effective at improving the hardness of the alloys, and the hardness values were barely modified. Apparently, the hardness enhancement after magnesium addition occurred due to a solute effect. To observe the phase effect of magnesium in aluminum alloys, binary alloys of aluminum-magnesium should be cast.
\end{abstract}

Keywords: CALPHAD; aluminum-copper-magnesium alloy; image analysis; ImageJ; JMatPro.

\section{INTRODUCTION}

Environmental legislation to reduce the emission of greenhouse gases has triggered an interest in weight reduction in vehicles to improve fuel economy (Miller et al., 2000). As a consequence, aluminum, being lightweight, offers itself as an alternative to steel for several body components and engine parts in automobiles. For this development and replacement of existing materials used in automobiles, examination of the effects of different alloying elements on the microstructure and mechanical properties of 
aluminum alloys is essential. For this purpose, a phase diagram is a starting point to understand the possible changes in the stability of different phases. Phase diagrams help to understand the compositional changes of a material from phase to phase and to predict the microstructure. They are the initial map for the design of a material to obtain the desired properties. They are constructed under equilibrium conditions through Gibbs free energy minimization. To investigate the changes in microstructure and properties under different conditions, modeling is useful as it reduces the need for expensive, complex and time-consuming experiments (Glicksman \& Hills, 2001). For simple systems like binary alloys, experiments can be performed easily. However, for multicomponent systems, dealing with the information obtained from complex experiments is quite cumbersome. Modeling enables calculation of multi-component phase diagrams, calculation of equilibria under a particular set of conditions of composition, pressure and temperature, and calculation of properties (Hillert, 1981). The CALPHAD (Calculation of Phase Diagram) method is currently the dominant approach used to model phase equilibria of a system (Saunders \& Miodownik, 1998). It deals with the mathematical expressions for thermodynamic properties of the phases. This method has enabled the determination of phases in complex systems under varying conditions. It is based on the Gibbs free energy concept. Through minimization of Gibbs free energy for a particular condition, calculation of phases can be done. Results obtained from the CALPHAD method have been shown to be close to the empirical values (Saunders, 2001).

To improve properties, alloying elements are added to the pure aluminum. These elements modify the phase diagram by changing the eutectic composition and temperature. The addition of copper in aluminum alloys results in the formation of Al${ }_{2} \mathrm{Cu}$ phase and allows precipitate hardening of the alloy (Xiao et al., 2002). Tensile strength and hardness values generally increase; however, ductility is reduced with copper addition. A low copper level is good for castability as too much copper leads to increased volumetric shrinkage and micro-porosity (Caceres et al., 1999). High copper content reduces the corrosion resistance of aluminum alloys (Hussey \& Wilson, 1998). In a similar fashion, minor addition of magnesium can provide a strengthening effect in aluminum alloys by precipitation hardening (Samuel \& Samuel, 1995). However, to have a bright surface finish or to enhance the anodizing characteristics, high magnesium content can be used (Brown, 1999; Davis, 1993). Addition of both magnesium and copper to aluminum alloys can improve strength and hardness (Girisha \& Sharma, 2012). However, it was not clear whether the solute strengthening effect was responsible for this increment of strength and hardness, or whether the formed stable phases took part in the strengthening. The current study concentrates on the microstructural effects of aluminum alloys by both copper and magnesium addition. Aluminum alloys of predefined compositions were cast and homogenized at $400^{\circ} \mathrm{C}$ for four hours. Afterwards, microstructures of as-cast and homogenized alloys were observed by optical and scanning electron microscopy (SEM). Thermodynamic modeling of the alloys was carried out, and the phases predicted were compared with results obtained from energy dispersive X-ray analysis (EDX) in SEM and image analysis of the microstructures.

\section{EXPERIMENTAL DETAILS}

Alloys having different copper and magnesium content were cast in a permanent metal mold using commercially pure ingots of aluminum (99.80\%), electrolytic copper 
(99.90\%) and magnesium ribbons. The metals were melted in a pit furnace at predetermined weight percentages. The molten metal was poured into the metal mold (made of cast iron) and cast samples of dimensions of 200x50x80 mm were made (Figure 1). Prior to the pouring of the hot metal, the mould was preheated to $200^{\circ} \mathrm{C}$. The composition of the alloys was determined using an optical emission spectrometer (Shimadzu PDA 700). The samples were cut to 50x30x20 mm using a vertical saw for homogenization treatment at $400^{\circ} \mathrm{C}$ for four hours in a BlueM Electric furnace. After heating, the samples were immediately put into water kept at room temperature.

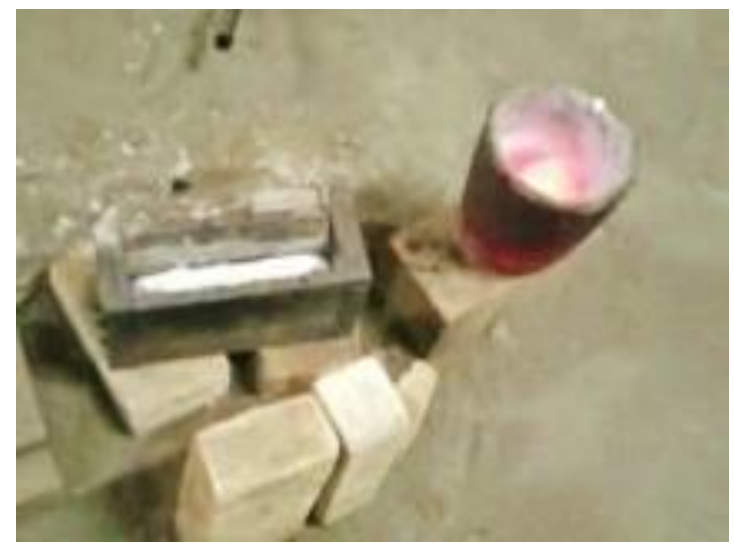

Figure 1. Casting of the alloys in a metal mold.

For microstructural observation, specimens were cut into $25 \times 25 \mathrm{~mm}$ size and ground and polished using the conventional metallographic sample preparation route. The microstructure of the specimens was observed in the un-etched condition using an Optica B-600 MET metallurgical microscope and images were acquired using the OpticaTM Vision Pro software package at the same resolution and the same RGB values. SEM was carried out on a Philips 525 FEGSEM with an energy dispersive Xray analysis (EDX) system in un-etched condition. The CALPHAD method was used to predict the phases developed in these alloys using the JMatPro software package (Saunders, 2001) for both equilibrium (Guo et al., 2005; Zhang, Han, \& Liu, 2006; Lacaze \& Valdes, 2005) and the non-equilibrium Scheil-Gulliver cooling condition (Ohno, Mirkovic, \& Schmid-Fetzer, 2006; Quested, Dinsdale, \& Greer, 2005). The hardness of the specimens was measured using a standard Rockwell Hardness testing machine in HRF scale with a $60 \mathrm{~kg}$ load and using a 1/16" diamond indenter. At least five readings were taken for each specimen at different locations to circumvent the possible effect of segregation of any alloying element.

Finally, microstructure obtained was analyzed using the ImageJ software package (Rasband, 1997) to determine area fractions of the phases present in the alloys. Prior to processing, images were converted to 8-bit gray scale. Shading correction was necessary for the images acquired from the optical microscope; otherwise, image analysis would not give accurate results. This was done for every single image using a graticule. After placing the graticule in the microscope, it was focused in a scratch-free zone and proper brightness was adjusted and an image was acquired. Then shading correction was done in ImageJ by using this image. The size of each pixel is necessary information before analyzing the images. This was done using ImageJ software. An image of the graticule at 200x magnification was taken in the same microscope. Then in ImageJ, a straight line of $100 \mu \mathrm{m}$ was drawn on the scale in the image. Then using the 
'Set Scale' command, it was found that $1 \mu \mathrm{m}$ contained 2.24 pixels. This scale was used for all the analyses which were done at 200x magnification. For different magnifications, a different scale was used. However, shading correction alone could not solve the problem of shadow in the images. Some shadows were found in the left top corner of the images. Therefore, the images were cropped to $1200 \times 950$ pixel dimensions to get rid of any shading problem. In ImageJ, a pre-written macro file was used to analyze the images. Two types of measurements were made: field measurements for the whole image and region measurements for the individual phases/particles. The whole area of the image (1200x950 pixels) was considered. So, a frame was not used to exclude the edges where some incomplete phases may exist. The reason is that excluding the edges may prevent some large particles from being considered. Before starting the measurements, an upper threshold was set for the first image of the specimen. Since the images were converted to gray values, the different regions can be distinguished using different gray value ranges. For example, a range of 0 to 20 of gray values should be enough to identify regions of black color. Therefore the phases having black color were identified using this range of gray values. The selected regions were eroded and dilated using open and closed binary operations. Using similar principles, different phases were identified and analyzed. If there was any relief surrounding the selected phases, it would result in shadows which would have a similar gray level; this would lead to incorrect measurements. So, a matrix was discriminated from all phases. Then slightly dilated (to include some shading) total black phases were subtracted from the segmented phases. Phase fractions of black phases and white/gray phases were thus calculated.

\section{RESULTS AND DISCUSSION}

\section{Chemical Composition of the Alloys}

The chemical composition of the as-cast alloys was determined by OES. Table 1 shows the chemical composition of alloys used in the current work. Though magnesium was added in higher amounts, most of it was not retained in the molten metal.

Table 1. Chemical composition of the as-cast aluminum alloys.

\begin{tabular}{llllll}
\hline Alloy & $\mathrm{Fe}$ & $\mathrm{Si}$ & $\mathrm{Cu}$ & $\mathrm{Mg}$ & $\mathrm{Al}$ \\
\hline Al-4Cu & 0.07 & 0.08 & 3.69 & 0.06 & Balance \\
Al-4Cu-0.5Mg & 0.10 & 0.05 & 3.51 & 0.30 & Balance \\
Al-4Cu-1Mg & 0.08 & 0.13 & 4.03 & 0.59 & Balance \\
Al-6Cu & 0.06 & 0.12 & 6.16 & 0.06 & Balance \\
Al-6Cu-0.5Mg & 0.02 & 0.09 & 5.45 & 0.55 & Balance \\
Al-6Cu-1Mg & 0.09 & 0.12 & 6.45 & 0.76 & Balance \\
\hline
\end{tabular}

\section{Phases Predicted in Modeling}

Figure 2 shows the predicted phase fractions for $\mathrm{Al}-4 \mathrm{Cu}$ alloy in the equilibrium condition, modeled by the CALPHAD method. Only $\mathrm{Al}_{2} \mathrm{Cu}$ was found to be stable in a higher amount. Since the alloys were homogenized, it was considered that there would be sufficient time for diffusion and the condition would approach the equilibrium cooling condition, instead of the solid state diffusion-less non-equilibrium Scheil- 
Gulliver condition. Such modeling was performed for each alloy and the phases predicted are given in Table 2. Only $\mathrm{Al}_{7} \mathrm{Cu}_{2} \mathrm{M}\left(\mathrm{M}=\right.$ metal), $\mathrm{Al}_{2} \mathrm{Cu}$ and $\mathrm{Mg}_{2} \mathrm{Si}$ phases are presented in the table since other phase fractions were very negligible. Since the homogenization temperature was $400^{\circ} \mathrm{C}$ (and the samples were quenched in water immediately), the phases present at that temperature should be retained at room temperature.

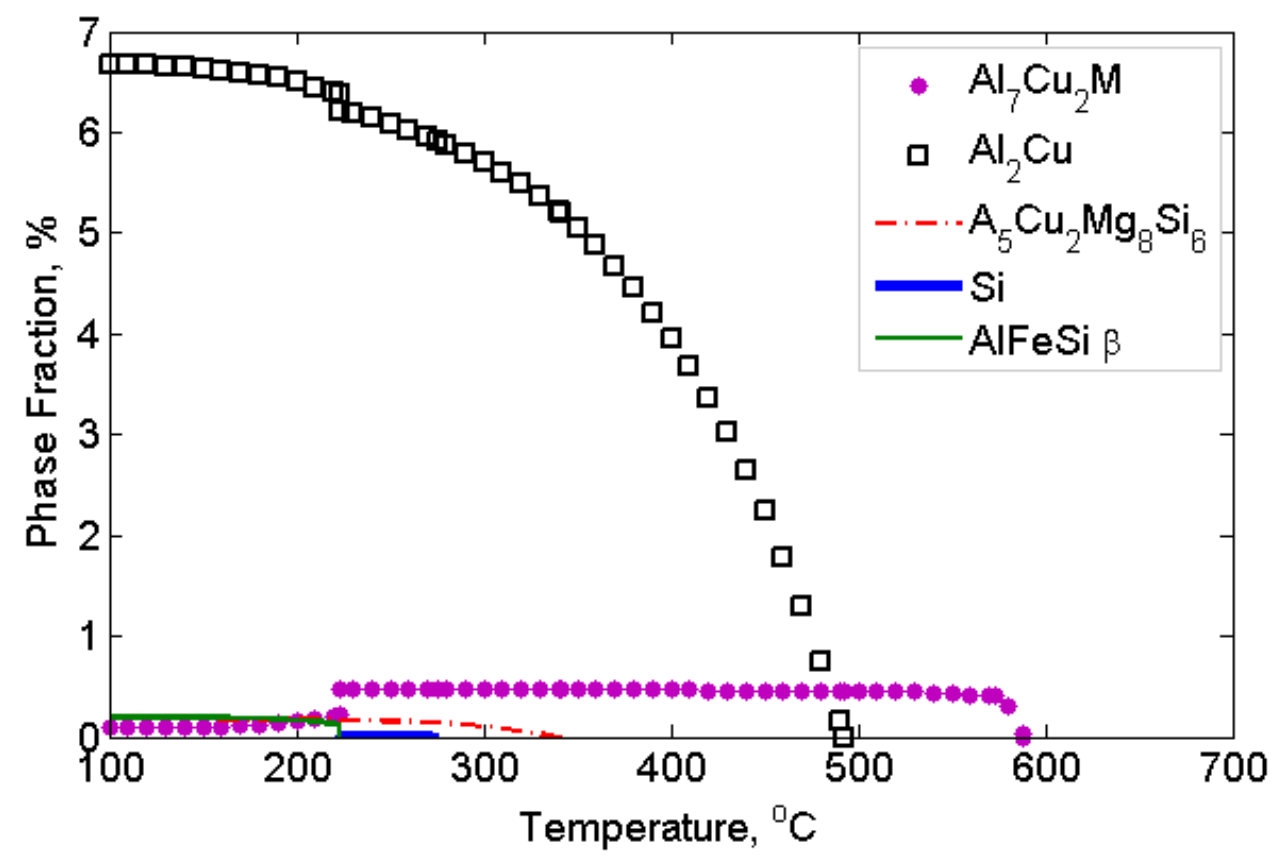

Figure 2. Predicted phase fractions for $\mathrm{Al}-4 \mathrm{Cu}$ alloy in the equilibrium condition in JMatPro software package

From Table 2, the effect of copper on second phases is evident. The phase fraction of $\mathrm{Al}_{2} \mathrm{Cu}$ phase was doubled by the addition of copper in the alloys. On the other hand, the effect of magnesium was not very significant. $\mathrm{Mg}_{2} \mathrm{Si}$ phase was formed due to the presence of magnesium in the alloys. In addition, $\mathrm{Al}_{7} \mathrm{Cu}_{2} \mathrm{M}(\mathrm{M}=$ metal) phase did not show any relationship with the amount of copper or magnesium present in the alloys.

Table 2. Predicted phase fractions of the alloys modeled by the CALPHAD method in the equilibrium condition

\begin{tabular}{lccc}
\hline \multicolumn{1}{c}{ Alloy } & $\mathrm{Al}_{7} \mathrm{Cu}_{2} \mathrm{M}$ & $\mathrm{Al}_{2} \mathrm{Cu}$ & $\mathrm{Mg}_{2} \mathrm{Si}$ \\
\hline $\mathrm{Al}-4 \mathrm{Cu}$ & 0.46 & 3.95 & - \\
$\mathrm{Al}-4 \mathrm{Cu}-0.5 \mathrm{Mg}$ & 0.66 & 3.34 & - \\
$\mathrm{Al}-4 \mathrm{Cu}-1 \mathrm{Mg}$ & 0.53 & 4.36 & 0.26 \\
$\mathrm{Al}-6 \mathrm{Cu}$ & 0.40 & 8.78 & - \\
$\mathrm{Al}-6 \mathrm{Cu}-0.5 \mathrm{Mg}$ & 0.13 & 7.33 & 0.16 \\
$\mathrm{Al}-6 \mathrm{Cu}-1 \mathrm{Mg}$ & 0.60 & 8.88 & 0.28 \\
\hline
\end{tabular}




\section{Phases Obtained Experimentally}

From CALPHAD modeling, it was predicted that the addition of copper and magnesium would result in the formation of certain phases in the aluminum matrix. The presence of these phases (Table 2) was confirmed by EDX analysis. The major phases predicted in the modeling are shown in Figure 3 and identified in the microstructure of $\mathrm{Al}-6 \mathrm{Cu}-1 \mathrm{Mg}$ alloy by SEM and EDX. Using spot EDX analysis, it was possible to determine the atomic fractions of those phases. Several spots were analyzed and their average atomic fractions were measured. The white phase in Figure 3 contains $68 \% \mathrm{Al}$ and $32 \% \mathrm{Cu}$ (at.\%), which comprises actual $\mathrm{Al}_{2} \mathrm{Cu}$ phase. Moreover, the black phase in Figure 3 apparently gives the composition of $\mathrm{Mg}_{2} \mathrm{Si}$. Therefore, it is ascertained that CALPHAD modeling can predict the phases present in the alloys considered with a close approximation. Figure 4 reveals some black phases present in $\mathrm{Al}-6 \mathrm{Cu}$ alloys with increasing magnesium content. These black phases are mainly magnesium-containing phases, as predicted from CALPHAD analysis and confirmed by EDX analysis.

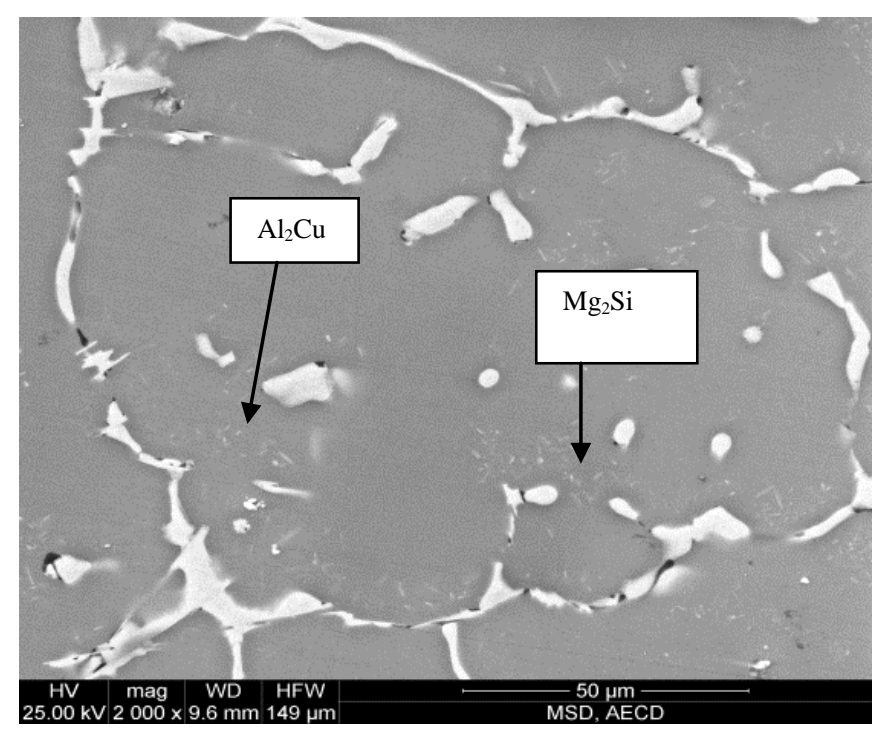

Figure 3. SEM micrograph of Al-6Cu-1Mg alloy. Identified phases are shown by arrows.

\section{Image Analysis of the Phases}

The image analysis technique was applied on the images from optical microscopy of the alloys to compare the phase fractions obtained. For convenience in image analysis, the phases are denoted as 'white phases' and 'black phases'. It was shown earlier that white phases were actually the phases containing aluminum and copper, and black phases were magnesium-containing $\mathrm{Mg}_{2} \mathrm{Si}$ phase. The phase fractions of these phases are shown in Table 3. If the data of Table 3 is compared with that of Table 2, it is clear that the prediction matches closely the actual phase fractions present in the alloys. It is noteworthy that few porosities were present in the cast alloys and that these were included in the black phase calculation. In summary, addition of copper increases the copper-containing phase $\mathrm{Al}_{2} \mathrm{Cu}$ irrespective of alloy composition. Similar to copper addition, the addition of magnesium increases the magnesium-containing phase $\mathrm{Mg}_{2} \mathrm{Si}$. 


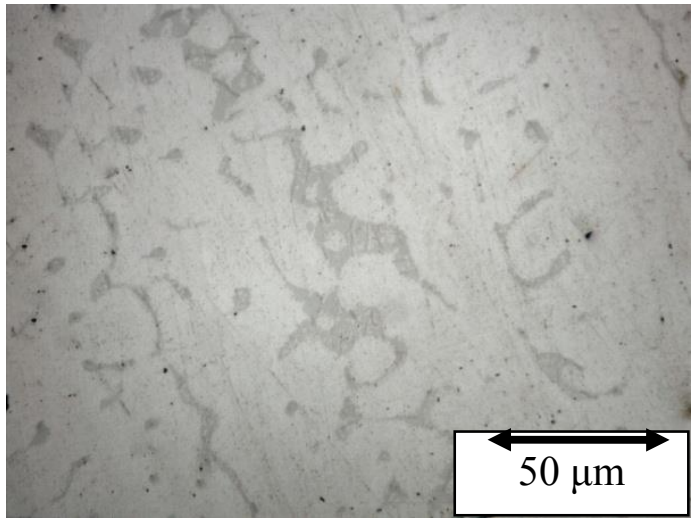

(a)

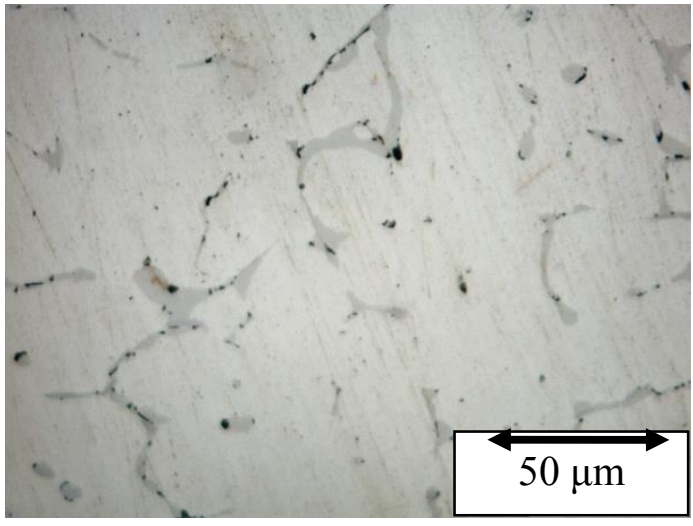

(b)

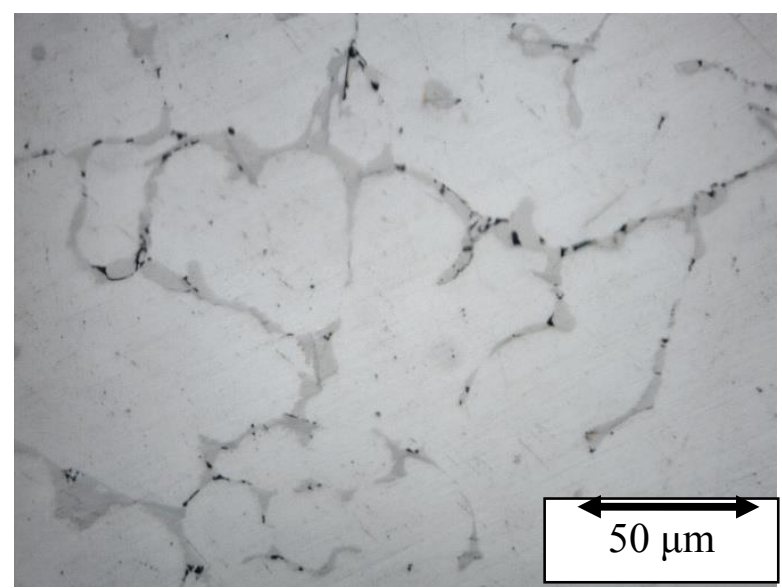

(c)

Figure 4: Optical micrographs showing microstructure of Al-6Cu alloys: (a) without any magnesium addition, (b) with $0.50 \mathrm{wt} \%$ magnesium addition, and (c) with $1 \mathrm{wt} \%$ magnesium addition

Table 3. Image analysis data of microstructures of the alloys; "white phases" resemble $\mathrm{Al}_{2} \mathrm{Cu}$ and $\mathrm{Al}_{7} \mathrm{Cu}_{2} \mathrm{M}$ phases and "black phase" resembles $\mathrm{Mg}_{2} \mathrm{Si}$ phases according to EDX analysis and some existing porosities

\begin{tabular}{lll}
\hline Alloys & White phases & Black phase \\
\hline Al-4Cu & $5.10 \pm 1.40$ & $0.16 \pm 0.05$ \\
Al-4Cu-0.5Mg & $5.34 \pm 2.12$ & $0.41 \pm 0.20$ \\
Al-4Cu-1Mg & $6.01 \pm 0.98$ & $0.64 \pm 0.25$ \\
Al-6Cu & $9.07 \pm 0.98$ & $0.12 \pm 0.08$ \\
Al-6Cu- $0.5 \mathrm{Mg}$ & $5.53 \pm 1.50$ & $0.35 \pm 0.17$ \\
Al-6Cu- $1 \mathrm{Mg}$ & $7.29 \pm 1.33$ & $0.45 \pm 0.19$ \\
\hline
\end{tabular}

\section{Effect of Composition on Hardness}

Homogenization treatment appears to affect the hardness of the aluminum alloys investigated. The hardness values of the alloys were, as expected, slightly reduced after homogenization treatment (Figure 5). Homogenization treatment was performed at $400^{\circ} \mathrm{C}$. Therefore, according to Figure 2, only $\mathrm{Al}_{2} \mathrm{Cu}$ and $\mathrm{Al}_{2} \mathrm{CuMg}$ phase were present 
in the homogenized and quenched samples. Moreover, the amount of $\mathrm{Al}_{2} \mathrm{Cu}$ was also reduced after homogenization treatment (e.g., 3.95\% at $400^{\circ} \mathrm{C}$ for $\mathrm{Al}-4 \mathrm{Cu}$ alloy), as is evident from Figure 2. As a result, the hardness values were slightly lower than the ascast values. This also implies that larger phase $\mathrm{Al}_{2} \mathrm{Cu}$ may also be responsible for hardness in these alloys. This is also true for $\mathrm{Al}-6 \mathrm{Cu}$ alloy, as seen from Figure $6 . \mathrm{Al}_{2} \mathrm{Cu}$ phase was $8.78 \%$ in that alloy at $400^{\circ} \mathrm{C}$ and the fraction was increased at lower temperature. It is noteworthy that the lower temperature resembles the as-cast condition of the alloys. The actual phase fraction of $\mathrm{Al}_{2} \mathrm{Cu}$ obtained from image analysis data (Table 3) also confirms that this particular phase contributes towards hardness modification. $\mathrm{Al}-4 \mathrm{Cu}$ alloy contains $5.10 \pm 1.40 \%$ white phases (eventually $\mathrm{Al}_{2} \mathrm{Cu}$ phase) and $\mathrm{Al}-6 \mathrm{Cu}$ alloy contains $9.07 \pm 0.98 \%$ white phases.

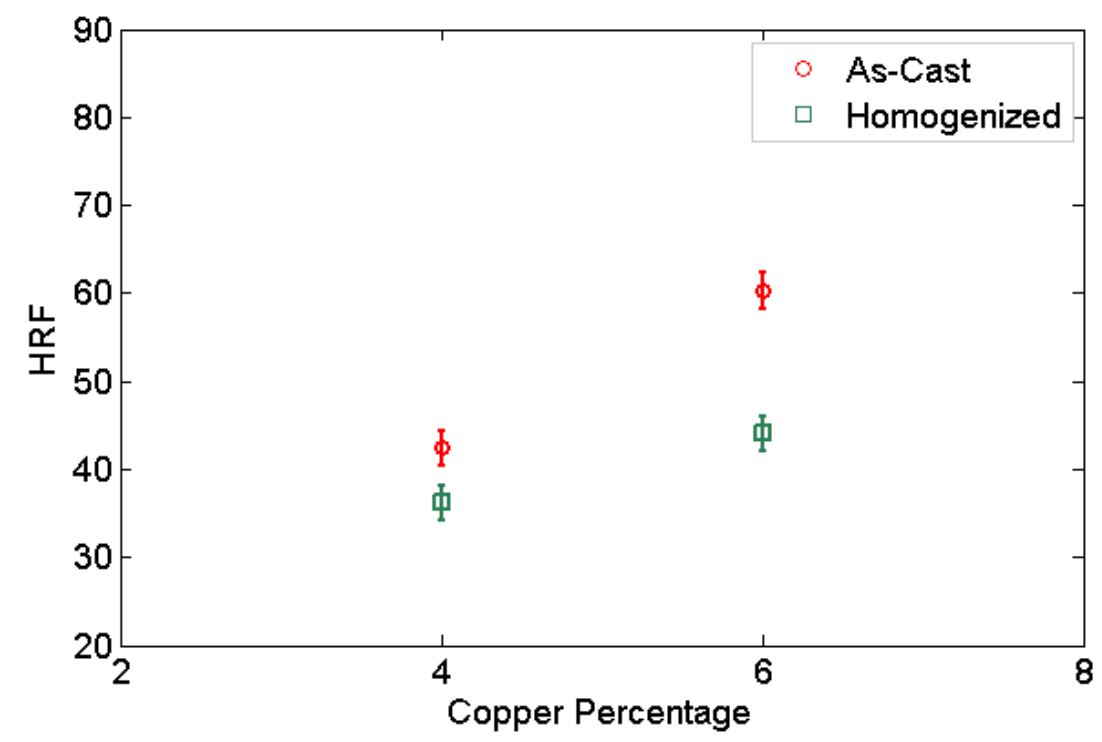

Figure 5. Hardness in HRF scale for both $\mathrm{Al}-4 \mathrm{Cu}$ and $\mathrm{Al}-6 \mathrm{Cu}$ alloys in the as-cast and homogenized condition

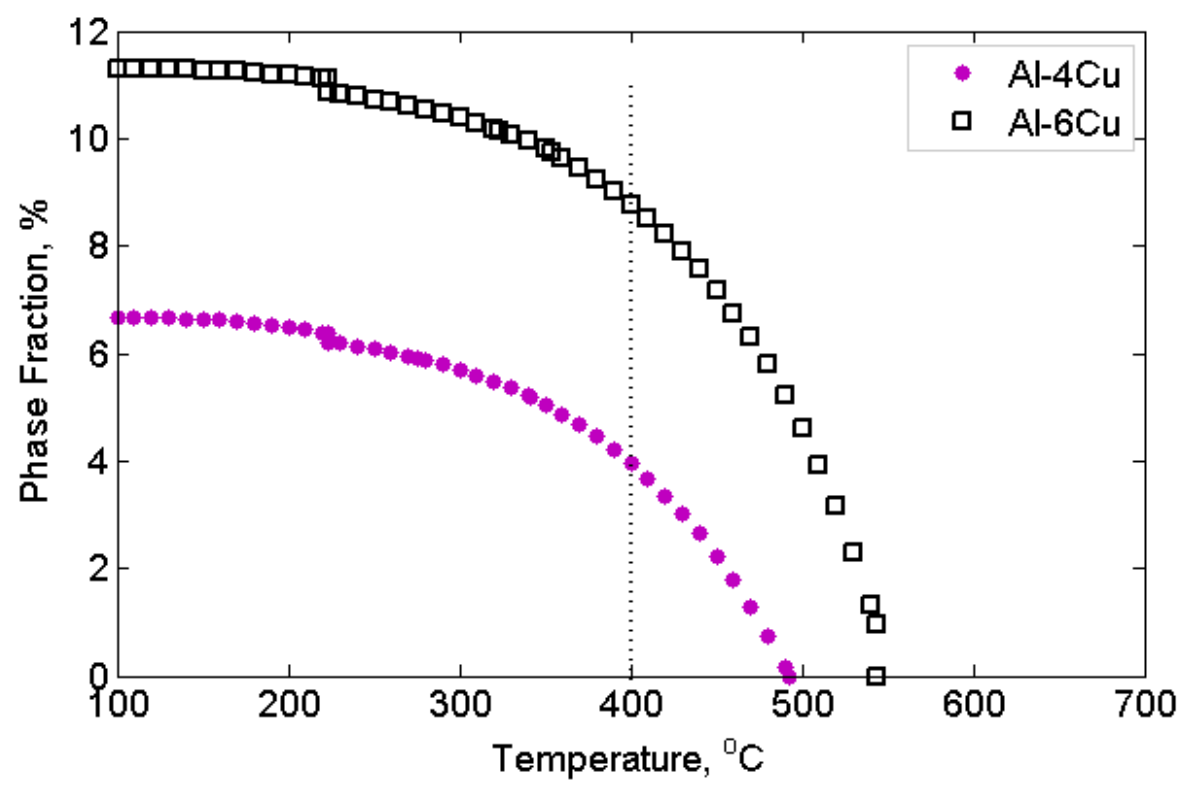

Figure 6. Fraction of $\mathrm{Al}_{2} \mathrm{Cu}$ in $\mathrm{Al}-4 \mathrm{Cu}$ and $\mathrm{Al}-6 \mathrm{Cu}$ at different temperatures 
Magnesium content was added to the alloys in different proportions, and thermodynamic modeling and hardness tests were performed to observe the effects of magnesium on properties, similar to the aluminum approach mentioned above. Surprisingly, the effect of magnesium, in the added portions, on the hardness values varied. Generally, magnesium contributes as a strengthening element in aluminum alloys. From Table 2, it is clear that magnesium forms a separate phase, $\mathrm{Mg}_{2} \mathrm{Si}$, only in the higher magnesium-containing alloys. On the other hand, the image analysis data reveals that some magnesium-containing phases existed in all alloys and their area fractions did not vary much, given the spread of error. However, Figure 7 shows that magnesium contributes to strengthening of the alloys, especially up to 0.50 magnesium wt $\%$ addition. This is in agreement with previous works (Girisha \& Sharma, 2012; Rana $\&$ Purohit, 2012). Above this content, magnesium was found to be not very effective in improving the hardness of the alloys investigated. Apparently, if the amount of magnesium is more than $0.50 \mathrm{wt} \%$, it is clear that excess magnesium precipitates out of the solution as magnesium-containing phases. This is also observed experimentally, as seen in the image analysis data in Table 3. Therefore, the increment of hardness values was obtained from the solute effect of magnesium in the matrix aluminum.

Obviously, as discussed above, $\mathrm{Mg}_{2} \mathrm{Si}$ was not very effective in strengthening considering the decreasing trend of hardness values, after $0.50 \mathrm{wt} \%$ magnesium, in Figure 7. $\mathrm{Mg}_{2} \mathrm{Si}$ phase stability is shown in Figure 8. It is obvious from this figure that in $\mathrm{Al}-4 \mathrm{Cu}-1 \mathrm{Mg}$ and $\mathrm{Al}-6 \mathrm{Cu}-1 \mathrm{Mg}$ alloys, magnesium is more likely to form a separate phase- $\mathrm{Mg}_{2} \mathrm{Si}$, and therefore, magnesium would not be very effective for hardness in these alloy conditions. In $\mathrm{Al}-4 \mathrm{Cu}-0.5 \mathrm{Mg}$ and $\mathrm{Al}-6 \mathrm{Cu}-0.5 \mathrm{Mg}$ alloys, the phase fraction of this phase is insignificant, meaning that magnesium remained in the solution and contributed to strengthening. Consequently, increasing magnesium content above this value did not promote a strengthening effect to any great extent.

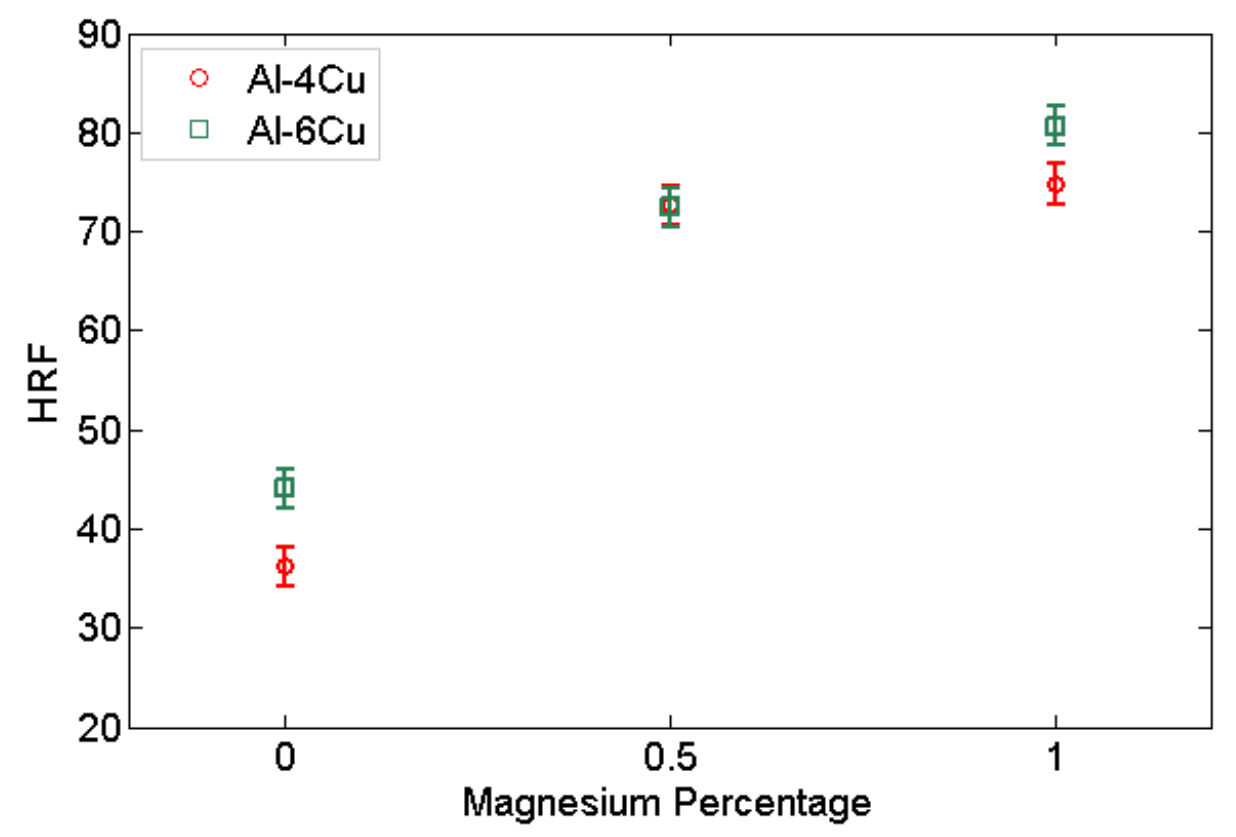

Figure 7. Hardness in $\mathrm{HRF}$ scale for both $\mathrm{Al}-4 \mathrm{Cu}$ and $\mathrm{Al}-6 \mathrm{Cu}$ alloys in the homogenized condition having different magnesium content. 


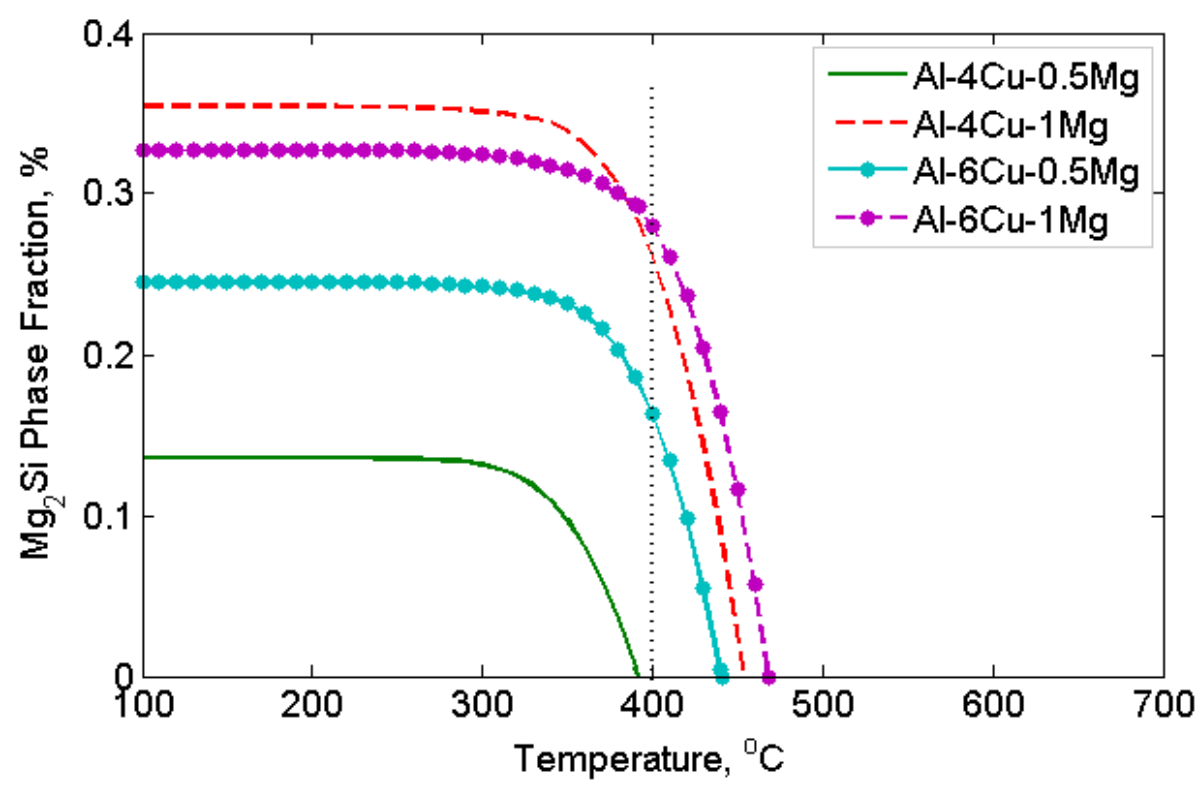

Figure 8. Fraction of $\mathrm{Mg}_{2} \mathrm{Si}$ in $\mathrm{Al}-4 \mathrm{Cu}$ and $\mathrm{Al}-6 \mathrm{Cu}$ alloys at different temperatures

\section{CONCLUSIONS}

(i) The CALPHAD method can closely predict the phases present in aluminum alloys. This was confirmed by image analysis of the phases present in the microstructure after homogenization. Since the alloys were homogenized, the equilibrium condition route was followed during modeling. $\mathrm{Al}_{2} \mathrm{Cu}, \mathrm{Mg}_{2} \mathrm{Si}$ and $\mathrm{Al}_{7} \mathrm{Cu}_{2} \mathrm{M}$ phases were predicted in thermodynamic modeling of the alloys and these three phases were also identified in EDX analysis.

(ii) With the addition of copper, the $\mathrm{Al}_{2} \mathrm{Cu}$ phase fraction was increased both in modeling and experimentally. With magnesium addition up to $0.50 \mathrm{wt} \%$, not much $\mathrm{Mg}_{2} \mathrm{Si}$ phase was present in the microstructure. With more magnesium addition, the $\mathrm{Mg}_{2} \mathrm{Si}$ phase fraction was increased. $\mathrm{Al}_{7} \mathrm{Cu}_{2} \mathrm{M}$ phase was found not to be affected by the composition of the alloys.

(iii) The addition of copper and magnesium results in an increase in the hardness of homogenized aluminum-copper-magnesium alloy, but with different trends. More $\mathrm{Al}_{2} \mathrm{Cu}$ phase is formed with more copper and, as a consequence, the hardness is improved. In contrast, with addition of magnesium up to $0.50 \mathrm{wt} \%$, most of the magnesium was retained in the matrix and a strengthening effect was observed from the increased hardness values. With further addition of magnesium, apparently, the hardness values were not increased as expected due to the formation of $\mathrm{Mg}_{2} \mathrm{Si}$ phases.

(iv) To understand the effect of magnesium, binary Al-Mg alloys should be cast and the aging responses of the alloys need to be understood.

\section{ACKNOWLEDGMENTS}

The authors are grateful to Bangladesh University of Engineering and Technology for providing funding for this work. 


\section{REFERENCES}

Brown, J. R. E. (1999). Foseco Non-Ferrous Foundryman's Handbook. Oxford: Butterworth Heinemann.

Caceres, C., Djurdjevic, M., Stockwell, T., \& Sokolowski, J. (1999). The effect of Cu content on the level of microporosity in Al-Si-Cu-Mg casting alloys. Scripta Materialia, 40, 631-637.

Davis, J. R. (1993). Aluminum and Aluminum Alloys. USA: ASM International.

Girisha, H. \& Sharma, K. (2012). Effect of magnesium on strength and microstructure of aluminium copper magnesium alloy. International Journal of Scientific \& Engineering Research, 2, 1-4.

Glicksman, M. E. \& Hills, R. N. (2001). Non-equilibrium segregation during alloy solidification. Philosophical Magazine A: Physics of Condensed Matter, Structure, Defects and Mechanical Properties, 81, 153-159.

Guo, Z., Saunders, N., Miodownik, A. P., \& Schillé, J. P. (2005). Modelling of materials properties and behaviour critical to casting simulation. Materials Science and Engineering: A, 413-414, 465-469.

Hillert, M. (1981). Some viewpoints on the use of a computer for calculating phase diagrams. Physica $B+C$, 103, 31-40.

Hussey, R. J. \& Wilson, J. 1998. Light Alloys Directory and Databook. London: Springer-Verlag (Chapman \& Hall).

Lacaze, J. \& Valdes, R. (2005). CALPHAD-type assessment of the Al-Mg-Si system. Monatshefte für Chemie/Chemical Monthly, 136, 1899-1907.

Miller, W. S., Zhuang, L., Bottema, J., Wittebrood, A. J., De Smet, P., Haszler, A., \& Vieregge, A. (2000). Recent development in aluminium alloys for the automotive industry. Materials Science and Engineering: A, 280, 37-49.

Ohno, M., Mirkovic, D., \& Schmid-Fetzer, R. (2006). Phase equilibria and solidification of Mg-rich Mg-Al-Zn alloys. Materials Science and Engineering: A, 421, 328337.

Quested, T., Dinsdale, A., \& Greer, A. (2005). Thermodynamic modelling of growthrestriction effects in aluminium alloys. Acta Materialia, 53, 1323-1334.

Rana, R. S. \& Purohit, R. (2012). Effect of magnesium enhancement on mechanical property and wear behaviour of LM6 aluminium alloy. International Journal of Scientific Engineering and Research, 3, 1-5.

Rasband, W. S. (1997). ImageJ. (1.43e ed.) Bethesda, MD, USA: U.S. National Institutes of Health, http://rsb.info.nih.gov/ij/.

Samuel, A. \& Samuel, F. (1995). Effect of alloying elements and dendrite arm spacing on the microstructure and hardness of an $\mathrm{Al}-\mathrm{Si}-\mathrm{Cu}-\mathrm{Mg}-\mathrm{Fe}-\mathrm{Mn}$ (380) aluminium die-casting alloy. Journal of Materials Science, 30, 1698-1708.

Saunders, N. (2001). Science and technology of light metals in the 21st century; the application of calculated phase equilibria to multi-bomponent aluminum alloys. Journal-Japan Institute of Light Metals, 51, 141-150.

Saunders, N. \& Miodownik, A. P. (1998). Calphad: Calculation of phase diagrams : A comprehensive guide. London: Pergamon Press.

Xiao, D. H., Wang, J. N., Ding, D. Y., \& Chen, S. P. (2002). Effect of Cu content on the mechanical properties of an $\mathrm{Al}-\mathrm{Cu}-\mathrm{Mg}-\mathrm{Ag}$ alloy. Journal of Alloys and Compounds, 343, 77-81.

Zhang, S., Han, Q. \& Liu, Z.-K. (2006). Thermodynamic modeling of the Al-Mg-Na system. Journal of Alloys and Compounds, 419, 91-97. 